UCRL-TR-202284

\title{
POINT 2004 A Temperature Dependent ENDF/B-VI, Release 8 Cross Section Library
}

\author{
by \\ Dermott E. Cullen \\ University of California \\ Lawrence Livermore National Laboratory \\ P.O. Box 808 \\ L-159 \\ Livermore, CA 94550 \\ tele: 510-423-7359 \\ E. Mail: cullen1@IInl.gov \\ website: http://www.llnl.gov/cullen1
}

April 1, 2004

Lawrence

Livermore

National

Laboratory

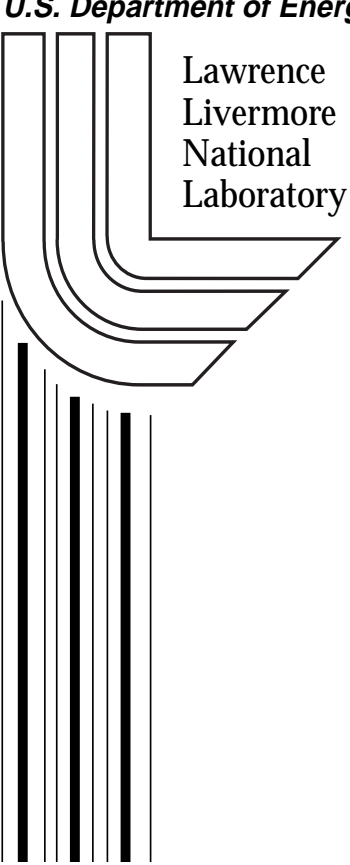

Approved for public release; further dissemination unlimited. 


\section{DISCLAIMER}

This document was prepared as an account of work sponsored by an agency of the United States Government. Neither the United States Government nor the University of California nor any of their employees, makes any warranty, express or implied, or assumes any legal liability or responsibility for the accuracy, completeness, or usefulness of any information, apparatus, product, or process disclosed, or represents that its use would not infringe privately owned rights. Reference herein to any specific commercial product, process, or service by trade name, trademark, manufacturer, or otherwise, does not necessarily constitute or imply its endorsement, recommendation, or favoring by the United States Government or the University of California. The views and opinions of authors expressed herein do not necessarily state or reflect those of the United States Government or the University of California, and shall not be used for advertising or product endorsement purposes.

Work performed under the auspices of the U. S. Department of Energy by the University of California Lawrence Livermore National Laboratory under Contract W-7405-Eng-48.

This report has been reproduced

directly from the best available copy.

Available to DOE and DOE contractors from the

Office of Scientific and Technical Information

P.O. Box 62, Oak Ridge, TN 37831

Prices available from (423) 576-8401

http://apollo.osti.gov/bridge/

Available to the public from the

National Technical Information Service

U.S. Department of Commerce

5285 Port Royal Rd.,

Springfield, VA 22161

http://www.ntis.gov/

OR

Lawrence Livermore National Laboratory

Technical Information Department's Digital Library

http://www.llnl.gov/tid/Library.html 
UCRL-TR-202284

\author{
POINT 2004 \\ A Temperature Dependent \\ ENDF/B-VI, Release 8 \\ Cross Section Library \\ by \\ Dermott E. Cullen \\ University of California \\ Lawrence Livermore National Laboratory \\ P.O. Box 808 \\ L-159 \\ Livermore, CA 94550 \\ tele: 510-423-7359 \\ E. Mail: cullen1@llnl.gov \\ website: http://www.llnl.gov/cullen1
}

April 1, 2004

\title{
Point 2004 versus Point 2003
}

Both the current Point 2004 and the previously published Point 2003 are based on exactly the same ENDF/B-VI, Release 8 data. The difference between them is the accuracy to which the reconstructed data is presented and the media on which they are distributed.

When Point 2003 was released constraints on the size of the data files to conveniently fit onto CDs resulted in my having to construct the cross section to a looser tolerance than I would have liked, and certainly looser than I routinely use in my applications. Even with this limitation Point 2003 contained about 1.8 Gigabytes of data, distributed on three CDs.

Point 2004 is distributed on a single DVD, rather than a series of CDs. This has allowed me to tighten the tolerance on the data to reconstruct cross sections at all energies and temperatures to $0.1 \%$ accuracy, which is what I routinely use in my applications. The result is a single DVD containing 4.3 Gigabyte of data. Note, that this library is almost two and a half times the size of the Point 2003 library, which should give you some idea of how much detail is added by tightening the tolerance; or if you prefer, how much detail was missing in earlier versions of this data.

For those familiar with the Point 2003 documentation, I will try to save you some time by pointing out that the remaining of this document is identical to the Point 2003, except where it refers to the difference in the contents of Point 2004 versus Point 2003. To help guide you through the remainder of this report, all changes are in red. 


\section{Introduction}

The ENDF/B data library has recently been updated and is now freely available through the National Nuclear Data Center (NNDC), Brookhaven National Laboratory. This most recent library is identified as ENDF/B-VI, Release 8 . Release 8 completely supersedes all preceding releases. Release 8 will be the last release of ENDF/B-VI; the next release of $\mathrm{ENDF} / \mathrm{B}$ data will be for the new ENDF/B-VII library.

As distributed the ENDF/B-VI, Release 8 data includes cross sections represented in the form of a combination of resonance parameters and/or tabulated energy dependent cross sections, nominally at 0 Kelvin temperature.

For use in applications this library has been processed into the form of temperature dependent cross sections at eight neutron reactor like temperatures, between 0 and 2100 Kelvin, in steps of 300 Kelvin. It has also been processed to five astrophysics like temperatures, 1, 10, $100 \mathrm{eV}, 1$ and $10 \mathrm{keV}$. For reference purposes, 300 Kelvin is approximately $1 / 40 \mathrm{eV}$, so that $1 \mathrm{eV}$ is approximately 12,000 Kelvin. At each temperature the cross sections are tabulated and linearly interpolable in energy.

All results are in the computer independent ENDF/B-VI character format [1], which allows the data to be easily transported between computers. In its processed form this library is approximately 4.3 gigabyte in size and is distributed on a single DVD.

\section{Earlier Versions of ENDF/B-VI}

Between the original distribution (Release 0) and Release 2 libraries, 74 evaluations were updated and distributed in July 1994 (see, UCRL-ID-117797). Between Release 2 and 3 libraries, 18 evaluations were updated and distributed in January 1996 (see, UCRL-ID124171). Between Release 0 and 3 no completely new evaluations were added to the library. Between Release 3 and 4(see, UCRL-ID-127776), 87 evaluations were updated and five completely new evaluations were added, namely for $\mathrm{Gd}^{152}, \mathrm{Gd}^{154}$, $\operatorname{Ir}^{191}$, $\operatorname{Ir}^{193}$ and $\mathrm{Pu}^{236}$. In additional the evaluation for natural $\mathrm{Cd}$ was deleted and replaced by evaluations for the individual isotopes. Between Release 4 and 7, 68 materials were modified; mostly to extend the cross sections from 20 to $150 \mathrm{MeV}$, and three new evaluations were added (14-Si-28, 14-Si-29, 14-Si-30). The result was a library of 324 evaluations.

For details, see the above mentioned three reports: UCRL-ID-117797, UCRL-ID-124171, and UCRL-ID-127776 and its revisions.

\section{ENDF/B-VI, Release 8 Data}

Note that the following comments refer to both Point 2003 and Point 2004. Between the earlier version of this library (POINT2000), which was based on release 7 data, and the current version (POINT2003 now Point 2004), which is based on release 8 data, a direct cross section by cross section comparison will show minor (fraction of a \%) differences 
in many cross sections, mainly due to improvements in the precision of the PREPRO2002 codes; these differences are not listed here. There are also many changes to the data that are not processed by PREPRO, this includes delayed neutron data, and neutron induced photon production data, that were not included in earlier versions of these evaluations; these changes are widespread throughout the library are also not listed here.

The following lists only significant changes to the evaluated neutron interaction cross sections (listed below in ascending ZA order),

\title{
Material Changes
}

\author{
4-Be-9 (n,t) 12 to $20 \mathrm{MeV}$ \\ 8-O-16 New cross sections \\ 16-S -Nat I removed bogus "fission widths" from resonance parameters \\ (note that this is the same correction I made for Release 7???) \\ 17-Cl-35 New evaluation \\ 17-Cl-37 New evaluation \\ 42-Mo-95 New elastic and capture \\ 43-Tc-99 New elastic and capture \\ 44-Ru-101 New elastic and capture \\ 45-Rh-103 New elastic and capture \\ 46-Pd-105 New elastic and capture \\ 47-Ag-109 New elastic and capture \\ 50-Sn-120 New above $10 \mathrm{keV}$ \\ 50-Sn-122 New above $10 \mathrm{keV}$ \\ 50-Sn-124 New above $10 \mathrm{keV}$ \\ 51-Sb-121 New elastic, capture and inelastic \\ 51-Sb-123 New elastic, capture and inelastic \\ 54-Xe-131 New elastic and capture \\ $60-\mathrm{Nd}-143$ New elastic and capture \\ 60-Nd-145 New elastic and capture \\ 62-Sm-147 New elastic and capture \\ 62-Sm-150 New elastic and capture \\ 62-Sm-151 New elastic and capture \\ 62-Sm-152 Minor changes at upper end of resolved resonance region \\ 64-Gd-155 New elastic and capture \\ 64-Gd-157 New elastic and capture \\ 91-Pa-232 New evaluation \\ 92-U- 232 New elastic, inelastic, fission and capture \\ 93-Np-236 New evaluation
}

The result is a library of 328 evaluations.

\section{PREPRO2002 Codes}

In addition to the changes in the ENDF/B-VI evaluations, it should be noted that between the last version of this report, where the PREPRO2000 codes were used, and the current 
version, where the PREPRO2002 codes were used, there have been major improvements in the ENDF/B Pre-processing codes. The major improvements were both in terms of improving the basic methods used by the codes and in terms of incorporating the latest ENDF/B-VI Formats and Procedures used by the current evaluations. The result is more accurate cross section data throughout the POINT2003 library.

WARNING - due to recent changes in ENDF/B-VI Formats and Procedures only the latest version of the ENDF/B Pre-processing codes, namely PREPRO2002, can be used to accurately process all current ENDF/B-VI evaluations. If you fail to heed this warning and you use any earlier versions of these codes the results will be inaccurate.

The PREPRO2002 codes run on virtually any computer, and are now available FREE online from the Nuclear Data Section, IAEA, Vienna, Austria, website at,

http://www-nds.iaea.or.at/ndspub/endf/prepro/

\section{Requesting this Data}

Please do not contact the author of this report to request this data; I do not have the resources necessary to directly respond to requests for this data. This data has been distributed to and is Internationally available from nuclear data/code centers throughout the World,

1) Within the United States: contact the National Nuclear Data Center, Brookhaven National Laboratory, Vicki McLane at services@bnlnd2.dne.bnl.gov

2) Within Western Europe: contact the OECD Nuclear Energy Agency/ Data Bank (NEA/DB), Paris, France, Enrico Sartori at sartori@ nea.fr

3) Otherwise: contact the Nuclear Data Section, international Atomic Energy Agency, Vienna, Austria, Vladimir Pronyaev at v.pronyaev@iaea.org

\section{Data Processing}

As distributed the original evaluated data includes cross sections represented in the form of a combination of resonance parameters and/or tabulated energy dependent cross sections, nominally at 0 Kelvin temperature. For use in applications, this data has been processed using the 2002 version of the ENDF/B Pre-processing codes (PREPRO2002) to produce temperature dependent, linearly interpolable in energy, tabulated cross sections, in the ENDF/B-VI format.

For use in applications this library has been processed into the form of temperature dependent cross sections at eight neutron reactor like temperatures, between 0 and 2100 Kelvin, in steps of $300 \mathrm{Kelvin}$. It has also been processed to five astrophysics like temperatures, 1, 10, $100 \mathrm{eV}, 1$ and $10 \mathrm{keV}$. For reference purposes, 300 Kelvin is approximately $1 / 40 \mathrm{eV}$, so that $1 \mathrm{eV}$ is approximately 12,000 Kelvin. At each temperature the cross sections are tabulated and linearly interpolable in energy.

The steps required and codes used to produce room temperature, linearly interpolable tabulated cross sections, in the ENDF/B-VI format, are described below (the name of 
each code in given in parenthesis; for details of each code see reference [2]).

Here are the steps, and PREPRO2002 codes, used to process the data, in the order in which the codes were used.

1) Linearly interpolable, tabulated cross sections (LINEAR)

2) Including the resonance contribution (RECENT)

3) Doppler broaden all cross sections to temperature (SIGMA1)

4) Check data, define redundant cross sections by summation (FIXUP)

5) Update evaluation dictionary in $\mathrm{MF} / \mathrm{MT}=1 / 451$ (DICTIN)

For the "cold" (0 Kelvin) data steps 1), 2) and 4), 5) were used. For the data at other temperatures, after steps 1) and 2), the data was Doppler broadened to each temperature using step 3), and the results were then made consistent with the ENDF/B formats and conventions using steps 4) and 5), to produce the final distributed data.

The result is linearly interpolable in energy, tabulated, temperature dependent cross sections, in the ENDF/B-VI format, ready to be used in applications.

Note - this processing only involved the energy dependent neutron cross sections. All other data in the evaluations, e.g., angular and energy distributions, was not affected by this processing, and is identical in all versions of the final results, i.e., it is the same in all of the directories, ORIGINAL, as well as K0 through K2100, and 1ev through 10kev, on the DVD.

\section{Accuracy of Results}

Each of the codes described above that was used to process data to obtain tabulated, linearly interpolable in energy cross sections, processed the data to within a user defined accuracy, or allowable uncertainty. The ENDF/B Pre-processing codes (PREPRO2002) are self-documenting, in the sense that the ENDF/B formatted output data that each code produces includes comments at the beginning of each evaluation defining the accuracy to which the cross sections were calculated. The combination of comments added by all of the codes defines the sequence and accuracy used by all of them. The accuracy is the same for all evaluations. Therefore, for exact details of the accuracy of the data, see the comments at the beginning of any evaluation. For use in Point 2004 all cross sections were reconstructed to within an accuracy of $0.1 \%$ at all energies and temperatures; this is beyond the accuracy to which we physically know this data, so that we can assume that the data processing does not add any significant additional error to the inherent error of the data.

\section{Contents of the Library}

This library contains all of the evaluations in the ENDF/B-VI general purpose library. The following table summarizes the contents of the ENDF/B-VI general purpose library. This library contains evaluations for 328 materials (isotopes or naturally occurring elemental mixtures of isotopes). 
This library does not contain data from special purpose ENDF/B-VI libraries, such as fission products, thermal scattering, photon interaction data. To obtain any of these special purpose libraries contact the National Nuclear Data Center, Brookhaven National Laboratory,

\section{ENDF@bnlnd2.dne.bnl.gov}

In this library each evaluation is stored as a separate file. The following table defines each material and the corresponding filename. The entire library is in the computer independent ENDF/B-VI character format, which allows the data to be easily transported between computers. The entire library requires approximately 4.3 gigabyte of storage and is distributed on a single DVD; see below for details of the DVD.

This library contains data for some metastable materials, which are indicated by an "M" at the end of their descriptions.

The majority of these evaluations are complete, in the sense that they include all cross sections over the energy range $10^{-5} \mathrm{eV}$ to at least $20 \mathrm{MeV}$. However, the following are only partial evaluations that either only contain single reactions and no total cross section $\left(\mathrm{Mg}^{24}, \mathrm{~K}^{41}, \mathrm{Ti}^{46}, \mathrm{Ti}^{47}, \mathrm{Ti}^{48}, \mathrm{Ti}^{50}\right.$ and $\left.\mathrm{Ni}^{59}\right)$, or do not include energy dependent cross sections above the resonance region $\left(\mathrm{Ar}^{40}, \mathrm{Mo}^{92}, \mathrm{Mo}^{98}, \mathrm{Mo}^{100}, \mathrm{In}^{115}, \mathrm{Sn}^{120}, \mathrm{Sn}^{122}\right.$ and $\left.\mathrm{Sn}^{124}\right)$.

\section{DVD Format and Layout}

The DVD were written using DVD-R format that can be read on almost any computer that has a DVD reader.

The DVD is divided into fifteen (15) directories,

DOCUMENT - A copy of this report in MSWord and PDF formats.

ORIGINAL - The original ENDF/B data before it was processed.

K0 $\quad-0$ Kelvin cross sections

K300 - 300 Kelvin cross sections

K600 - 600 Kelvin cross sections

K900 - 900 Kelvin cross sections

K1200 - 1200 Kelvin cross sections

K1500 - 1500 Kelvin cross sections

K1800 - 1800 Kelvin cross sections

K2100 - 2100 Kelvin cross sections

$1 \mathrm{eV} \quad-1 \mathrm{eV}$ cross sections

$10 \mathrm{eV} \quad-10 \mathrm{eV}$ cross sections

$100 \mathrm{eV} \quad-100 \mathrm{eV}$ cross sections

$1 \mathrm{keV} \quad-1 \mathrm{keV}$ cross sections

$10 \mathrm{keV} \quad-10 \mathrm{keV}$ cross sections 
With the exception of DOCUMENT, each of these directories contains 328 files, one file for each evaluation. Each file is a complete ENDF/B "tape" [1], including a starting "tape" identification line, and ending with a "tape" end line [1]. In this form, each file can be used by a wide variety of available computer codes that treat data in the ENDF/B format, e.g., all of the PREPRO codes.

\section{The Effects of Temperature and Doppler Broadening}

For those readers who are not familiar with the effects of temperature and Doppler broadening on neutron cross sections and transport, I suggest that you read references [3] and [4], listed below.

Users of neutron cross sections should be aware that there are several important effects of temperature and Doppler broadening,

1) There is the well known effect in the neutron resonance region, where as the temperature increases resonances become broader, hence the name Doppler broadening. Figure 1 illustrates the effect of temperature on the $\mathrm{U}^{238}$ capture cross section for neutron reactor like temperatures, and figure 2 illustrates this effect for astrophysical like temperatures. These figures each contain four sub-figures, with each sub-figure comparing cross sections at two progressively higher temperatures. In both figure 1 and 2 each sub-figure shows exactly the same energy and cross section range. From these figures we can see that as temperature increases the peaks of the resonances become lower, and the minima between resonances become higher. At extremely high temperature the entire resonance structure disappears and the cross sections approaches a simple $1 / \mathrm{v}$ shape (where $\mathrm{v}$ is the neutron speed). This temperature effect will have a very important effect on resonance self-shielding in any neutron transport calculation. You should note from these figures that due to the large resonance spacing in $\mathrm{U}^{\mathbf{2 3 8}}$ the resonance structure can still be seen up to surprisingly high temperatures.

To understand the importance of considering temperature we should consider reaction rates, such as captures/second, in various systems. In optically thin systems (few mean free paths dimensions) the flux will be unshielded, and our reaction rates will be defined by a simple cross section average,

Unshielded Capture $=\int_{E 1}^{E 2}[\Sigma c(E) \phi(E)] d E=$ capture cross section times neutron flux

In optically thick systems (many mean free paths dimensions) the flux will be shielded (the flux is suppressed by the total cross section) and our reaction rates must include the effect of self-shielding on the cross section average,

Shielded Capture $=\int_{E 1}^{E 2}[\Sigma c(E) \phi(E) / \Sigma t(E)] d E=$ including one over total cross section 
Consider for example the U238 capture cross section between 1 and $10 \mathrm{keV}$ as shown in fig. 1 and 2. If we calculate the unshielded and shielded average capture cross section for the energy interval over the range of temperatures shown in figs. 1 and 2, we obtain the results shown below in table 1 .

What we see from these results is that the unshielded average capture cross section is virtually independent of temperature, being about 1 barn over the entire temperature range. In contrast the shielded average cross section varying by over a factor of three between the $0 \mathrm{~K}$ average ( 0.293 barns) and the $10 \mathrm{keV}$ average ( 0.939 barns). The point to learn from this is that without including the effect of self-shielding in multi-group calculations, temperature has very little effect on the average cross sections, which is quite simply wrong for optically thick systems.

\begin{tabular}{|c|c|c|}
\hline Temp. & $\begin{array}{l}\text { Unshielded } \\
\text { (barns) }\end{array}$ & $\begin{array}{l}\text { Shielded } \\
\text { (barns) }\end{array}$ \\
\hline $0 \mathrm{~K}$ & 0.996 & 0.293 \\
\hline $300 \mathrm{~K}$ & 0.966 & 0.526 \\
\hline $600 \mathrm{~K}$ & 0.996 & 0.576 \\
\hline $1,200 \mathrm{~K}$ & 0.996 & 0.630 \\
\hline $12,000 \mathrm{~K}(1 \mathrm{eV})$ & 0.996 & 0.799 \\
\hline $10 \mathrm{eV}$ & 0.998 & 0.905 \\
\hline $100 \mathrm{eV}$ & 1.000 & 0.933 \\
\hline $1 \mathrm{keV}$ & 1.004 & 0.935 \\
\hline $10 \mathrm{keV}$ & 1.007 & 0.939 \\
\hline
\end{tabular}

2) Another, less well known, effect of Doppler broadening is at lower energies where as temperature increases the low energy constant scattering cross section increases and at very low energies approaches a simple $1 / \mathrm{v}$ shape (where $\mathrm{v}$ is the neutron speed); this effect is explained in detail in ref [3]. Figure 3 illustrates the effect of temperature on the hydrogen total cross section. From this figure we can see that starting from a "cold" (0 Kelvin) cross section that is constant at about 20 barns, as temperature increases the cross section increases. Compared to the "cold" 20 barn cross section, at thermal energy the Doppler broadened cross section is about 30 barns, i.e., $50 \%$ higher. Note also from this figure that this effect extends well above thermal energy. For example, at 300 Kelvin the thermal energy is $0.0253 \mathrm{eV}$, but we can see this effect up to about $1 \mathrm{eV}$. From the lower half of figure 2 we can see that at very low energy the cross section approaches a simple $1 / \mathrm{v}$ shape (where $\mathrm{v}$ is the neutron speed) and the cross sections at various temperatures become proportional to one another. This effect on the cross sections at low energy is very important for thermal and low energy neutron systems.

3) Yet another important effect of temperature is that at lower energies neutrons do not slow down in energy as quickly and neutron scatter can even result in the upscatter of neutrons, i.e., when neutrons scatter they can gain, rather than lose, energy. This is a well known effect at low energies, where thermal scattering law data or a free gas model is used to model the interaction of neutrons with target atoms that are moving about with thermal motion. This effect can also be important at higher energies, particularly near narrow resonances, where thermal motion of the target atoms can cause neutrons to slightly upscatter, but even slight upscatter can cause a neutron to scatter from below to 
above the energy of a very narrow resonance. See reference [4], below for a routine designed to be used in conjunction with the SIGMA1 method of Doppler broadening [3], to handle neutron thermal scattering. This routine [4] is completely compatible for use with the cross sections included here, since these cross sections were Doppler broadened using the SIGMA1 method [3]. The combination of SIGMA1 [3] Doppler broadened cross sections and THERMAL [4] to handle thermal scattering, is currently used in the TART Monte Carlo transport code [5].

\section{Acknowledgments}

I thank Vicki McLane and Marion Blennau, of the National Nuclear Data Center (NNDC), Brookhaven National Laboratory, for supplying the original ENDF/B, Release 8 data, used in this project. I thank Vladimir Pronyaev and Kevin McLaughlin, of the Nuclear Data Section, International Atomic Energy Agency, for supplying the ENDF/B Pre-processing codes, PREPRO2002, used in this project. I thank Bob MacFarlane, Maurice Greene, and Mike Dunn, for benchmarking their cross section processing codes (NJOY and AMPX) against the PREPRO2002 codes. These comparisons have led to significant improvements in the accuracy and reliability of the results produced by all three codes (NJOY, AMPX, PREPRO).

\section{References}

[1] Data Formats and Procedures for the Evaluated Nuclear Data File ENDF-6, BNLNCS-44945, Rev. 11/95, edited by V. McLane, et.al. National Nuclear Data Center, Brookhaven National Lab. http://www.nndc.bnl.gov/nndescr/documents/endf/endf102/

[2] "PREPRO2002: The 2002 ENDF/B Pre-Processing Codes," by D.E. Cullen, Nuclear Data Section, International Atomic Energy Agency, Vienna, Austria, IAEA-NDS-39, Rev. 11, April 1, 2002. http://www-nds.iaea.or.at/ndspub/endf/prepro/

[3] "Exact Doppler Broadening of Tabulated Cross Sections," by D.E. Cullen and C.R. Weisbin, Nuclear Science and Engineering 60, p. 199 (1975)

[4] "THERMAL: A Routine Designed to Calculate Neutron Thermal Scattering," by D.E. Cullen, Lawrence Livermore National Laboratory, UCRL-ID-120560-Rev-1, Sept. 1995. http://www.llnl.gov/cullen1/thermal.htm

[5] "TART2002: A Coupled Neutron-Photon 3-D, Time Dependent, Combinatorial Geometry Monte Carlo Transport Code," by D.E. Cullen, Lawrence Livermore National Laboratory, UCRL-ID-126455, Rev. 4, Nov. 2002. http://www.llnl.gov/cullen1/mc.htm 
ENDF/B-VI, Release 8

ENDF/B-VI Release 8 Library ( $\mathrm{Z}=1$ to 51) New Release 8 Evaluations in RED

\begin{tabular}{|c|c|}
\hline Filename & Material \\
\hline $\mathrm{ZA} 001001$ & $1-\mathrm{H}-1$ \\
\hline $\mathrm{ZA} 001002$ & $1-\mathrm{H} \quad-2$ \\
\hline $\mathrm{ZA} 001003$ & $1-\mathrm{H}-3$ \\
\hline $\mathrm{ZA} 002003$ & $2-\mathrm{He}-3$ \\
\hline ZA002004 & $2-\mathrm{He}-4$ \\
\hline $\mathrm{ZA} 003006$ & $3-\mathrm{Li}-6$ \\
\hline ZA003007 & $3-\mathrm{L} i-7$ \\
\hline ZA004009 & $4-\mathrm{Be}-9$ \\
\hline $\mathrm{ZA} 005010$ & $5-B-10$ \\
\hline $\mathrm{ZA} 005011$ & $5-B-11$ \\
\hline $\mathrm{ZA} 006000$ & 6-C -Nat \\
\hline $\mathrm{ZA} 007014$ & $7-N \quad-14$ \\
\hline $\mathrm{ZA} 007015$ & $7-N-15$ \\
\hline $\mathrm{ZA} 008016$ & $8-0-16$ \\
\hline ZA008017 & $8-0-17$ \\
\hline $\mathrm{ZA} 009019$ & $9-F-19$ \\
\hline $\mathrm{ZA} 011023$ & $11-\mathrm{Na}-23$ \\
\hline ZA012000 & $12-\mathrm{Mg}-\mathrm{Nat}$ \\
\hline ZA012024 & $12-\mathrm{Mg}-24$ \\
\hline ZA013027 & $13-\mathrm{Al}-27$ \\
\hline $\mathrm{ZA} 014000$ & 14-Si-Nat \\
\hline $\mathrm{ZA} 014028$ & $14-S i-28$ \\
\hline $\mathrm{ZA} 014029$ & $14-S i-29$ \\
\hline $\mathrm{ZA} 014030$ & $14-\mathrm{Si}-30$ \\
\hline ZA015031 & $15-\mathrm{P}-31$ \\
\hline $\mathrm{ZA} 016000$ & $16-\mathrm{S}-\mathrm{Nat}$ \\
\hline ZA016032 & $16-\mathrm{s}-32$ \\
\hline $\mathrm{ZA} 017000$ & 17-Cl-Nat \\
\hline $\mathrm{ZA} 017035$ & $17-\mathrm{Cl}-35$ \\
\hline $\mathrm{ZA} 017037$ & $17-\mathrm{Cl}-37$ \\
\hline $\mathrm{ZA} 018040$ & $18-\mathrm{Ar}-40$ \\
\hline ZA019000 & 19-K -Nat \\
\hline $\mathrm{ZA} 019041$ & $19-\mathrm{K}-41$ \\
\hline $\mathrm{ZA} 020000$ & 20-Ca-Nat \\
\hline $\mathrm{ZA} 021045$ & $21-S c-45$ \\
\hline $\mathrm{ZA} 022000$ & 22-Ti-Nat \\
\hline $\mathrm{ZA} 022046$ & $22-\mathrm{Ti}-46$ \\
\hline $\mathrm{ZA} 022047$ & $22-T i-47$ \\
\hline $\mathrm{ZA} 022048$ & $22-T i-48$ \\
\hline $\mathrm{ZA0} 22050$ & $22-\mathrm{Ti}-50$ \\
\hline $\mathrm{ZA0} 23000$ & $23-\mathrm{V}-\mathrm{Nat}$ \\
\hline ZA024050 & $24-\mathrm{Cr}-50$ \\
\hline ZA024052 & $24-\mathrm{Cr}-52$ \\
\hline ZA024053 & $24-\mathrm{Cr}-53$ \\
\hline $\mathrm{ZA} 024054$ & $24-\mathrm{Cr}-54$ \\
\hline $\mathrm{ZA} 025055$ & $25-M n-55$ \\
\hline $\mathrm{ZA} 026054$ & $26-\mathrm{Fe}-54$ \\
\hline $\mathrm{ZA} 026056$ & $26-\mathrm{Fe}-56$ \\
\hline $\mathrm{ZA} 026057$ & $26-\mathrm{Fe}-57$ \\
\hline $\mathrm{ZA} 026058$ & $26-\mathrm{Fe}-58$ \\
\hline $\mathrm{ZA} 027059$ & 27-Co-59 \\
\hline ZA028058 & $28-\mathrm{Ni}-58$ \\
\hline ZA028059 & $28-\mathrm{Ni}-59$ \\
\hline $\mathrm{ZA} 028060$ & $28-\mathrm{Ni}-60$ \\
\hline $\mathrm{ZA} 028061$ & $28-\mathrm{Ni}-61$ \\
\hline
\end{tabular}

\begin{tabular}{|c|c|}
\hline Filename & Material \\
\hline $\mathrm{ZA028062}$ & $28-N i-62$ \\
\hline $\mathrm{ZA028064}$ & $28-N i-64$ \\
\hline $\mathrm{ZA029063}$ & $29-\mathrm{Cu}-63$ \\
\hline ZA029065 & $29-\mathrm{Cu}-65$ \\
\hline $\mathrm{ZA0} 31000$ & 31-Ga-Nat \\
\hline $\mathrm{ZA0} 32072$ & $32-\mathrm{Ge}-72$ \\
\hline ZA032073 & $32-\mathrm{Ge}-73$ \\
\hline ZA032074 & $32-\mathrm{Ge}-74$ \\
\hline ZA032076 & $32-\mathrm{Ge}-76$ \\
\hline ZA033075 & $33-A s-75$ \\
\hline ZA034074 & $34-\mathrm{Se}-74$ \\
\hline ZA034076 & $34-\mathrm{Se}-76$ \\
\hline $\mathrm{ZA0} 34077$ & $34-\mathrm{Se}-77$ \\
\hline ZA034078 & $34-S e-78$ \\
\hline ZA034080 & $34-S e-80$ \\
\hline $\mathrm{ZA034082}$ & $34-S e-82$ \\
\hline ZA035079 & $35-\mathrm{Br}-79$ \\
\hline ZA035081 & $35-B r-81$ \\
\hline ZA036078 & $36-\mathrm{Kr}-78$ \\
\hline ZA036080 & $36-\mathrm{Kr}-80$ \\
\hline $\mathrm{ZA036082}$ & $36-K r-82$ \\
\hline ZA036083 & $36-\mathrm{Kr}-83$ \\
\hline $\mathrm{ZA0} 036084$ & $36-K r-84$ \\
\hline ZA036085 & $36-K r-85$ \\
\hline ZA036086 & $36-K r-86$ \\
\hline ZA037085 & $37-R b-85$ \\
\hline ZA037086 & $37-R b-86$ \\
\hline ZA037087 & $37-\mathrm{Rb}-87$ \\
\hline $\mathrm{ZA038084}$ & $38-S r-84$ \\
\hline $\mathrm{ZA0} 08086$ & $38-S r-86$ \\
\hline ZA038087 & $38-S r-87$ \\
\hline ZA038088 & $38-S r-88$ \\
\hline ZA038089 & $38-S r-89$ \\
\hline ZA038090 & $38-\mathrm{Sr}-90$ \\
\hline ZA039089 & $39-Y-89$ \\
\hline ZA039090 & $39-Y-90$ \\
\hline ZA039091 & $39-Y-91$ \\
\hline $\mathrm{ZA040000}$ & 40-Zr-Nat \\
\hline $\mathrm{ZA040090}$ & $40-Z r-90$ \\
\hline ZA040091 & $40-Z r-91$ \\
\hline $\mathrm{ZA040092}$ & $40-\mathrm{Zr}-92$ \\
\hline ZA040093 & $40-Z r-93$ \\
\hline ZA040094 & $40-Z r-94$ \\
\hline ZA040095 & $40-Z r-95$ \\
\hline ZA040096 & $40-Z r-96$ \\
\hline ZA041093 & $41-N b-93$ \\
\hline ZA041094 & $41-\mathrm{Nb}-94$ \\
\hline ZA041095 & $41-N b-95$ \\
\hline $\mathrm{ZA0} 042000$ & 42-Mo-Nat \\
\hline ZA042092 & 42-Mo-92 \\
\hline ZA042094 & $42-\mathrm{Mo}-94$ \\
\hline ZA042095 & 42-Mo-95 \\
\hline ZA042096 & $42-M o-96$ \\
\hline $\mathrm{ZA} 042097$ & 42-Mo-97 \\
\hline ZA042098 & 42-Mo-98 \\
\hline
\end{tabular}

\begin{tabular}{|c|c|}
\hline Filename & Material \\
\hline ZA042099 & 42-Mo-99 \\
\hline $\mathrm{ZA0} 42100$ & $42-\mathrm{Mo}-100$ \\
\hline ZA043099 & 43-Tc-99 \\
\hline ZA044096 & $44-R u-96$ \\
\hline ZA044098 & $44-R u-98$ \\
\hline ZA044099 & $44-R u-99$ \\
\hline ZA044100 & $44-R u-100$ \\
\hline ZA0 44101 & $44-\mathrm{Ru}-101$ \\
\hline $\mathrm{ZA0} 44102$ & $44-R u-102$ \\
\hline $\mathrm{ZA0} 44103$ & $44-R u-103$ \\
\hline $\mathrm{ZA0} 44104$ & $44-\mathrm{Ru}-104$ \\
\hline $\mathrm{ZA0} 44105$ & $44-R u-105$ \\
\hline $\mathrm{ZA044106}$ & $44-R u-106$ \\
\hline $\mathrm{ZA0} 45103$ & $45-\mathrm{Rh}-103$ \\
\hline ZA045105 & $45-R h-105$ \\
\hline ZA0 46102 & $46-P d-102$ \\
\hline $\mathrm{ZA0} 46104$ & $46-P d-104$ \\
\hline ZA0 46105 & $46-P d-105$ \\
\hline ZA0 46106 & $46-P d-106$ \\
\hline ZA0 46107 & $46-P d-107$ \\
\hline ZA0 46108 & $46-P d-108$ \\
\hline $\mathrm{ZA0} 46110$ & $46-P d-110$ \\
\hline $\mathrm{ZA047107}$ & $47-\mathrm{Ag}-107$ \\
\hline ZA047109 & $47-\mathrm{Ag}-109$ \\
\hline $\mathrm{ZA0} 47111$ & $47-\mathrm{Ag}-111$ \\
\hline ZA048106 & $48-C d-106$ \\
\hline ZA048108 & $48-C d-108$ \\
\hline ZA0 48110 & $48-C d-110$ \\
\hline ZA0 48111 & $48-C d-111$ \\
\hline $\mathrm{ZA0} 48112$ & $48-C d-112$ \\
\hline ZA0 48113 & $48-C d-113$ \\
\hline $\mathrm{ZA0} 48114$ & $48-C d-114$ \\
\hline $\mathrm{ZA0} 48115 . \mathrm{M}$ & $48-C d-115 m$ \\
\hline ZA048116 & $48-C d-116$ \\
\hline $\mathrm{ZA0} 49000$ & 49-In-Nat \\
\hline ZA0 49113 & $49-I n-113$ \\
\hline ZA049115 & $49-I n-115$ \\
\hline ZA050112 & $50-\mathrm{Sn}-112$ \\
\hline ZA050114 & $50-\mathrm{Sn}-114$ \\
\hline ZA050115 & $50-\mathrm{Sn}-115$ \\
\hline ZA050116 & $50-\mathrm{Sn}-116$ \\
\hline ZA050117 & $50-\mathrm{Sn}-117$ \\
\hline ZA050118 & $50-\mathrm{Sn}-118$ \\
\hline ZA050119 & $50-\mathrm{Sn}-119$ \\
\hline ZA050120 & $50-\mathrm{Sn}-120$ \\
\hline ZA050122 & $50-\mathrm{Sn}-122$ \\
\hline ZA050123 & $50-\mathrm{Sn}-123$ \\
\hline ZA050124 & $50-\mathrm{Sn}-124$ \\
\hline ZA050125 & $50-\mathrm{Sn}-125$ \\
\hline ZA050126 & $50-\mathrm{Sn}-126$ \\
\hline ZA051121 & $51-S b-121$ \\
\hline ZA051123 & $51-\mathrm{Sb}-123$ \\
\hline ZA051124 & $51-S b-124$ \\
\hline ZA051125 & $51-\mathrm{Sb}-125$ \\
\hline
\end{tabular}


ENDF/B-VI, Release 8

ENDF/B-VI Release 8 Library ( $\mathrm{Z}=51$ to 99) New Release 8 Evaluations in RED

\begin{tabular}{|c|c|}
\hline Filename & Material \\
\hline ZA051126 & $51-S b-126$ \\
\hline ZA052120 & $52-\mathrm{Te}-120$ \\
\hline ZA052122 & $52-\mathrm{Te}-122$ \\
\hline ZA052123 & $52-\mathrm{Te}-123$ \\
\hline ZA052124 & $52-\mathrm{Te}-124$ \\
\hline ZA052125 & $52-\mathrm{Te}-125$ \\
\hline ZA052126 & $52-\mathrm{Te}-126$ \\
\hline ZA052127.M & $52-\mathrm{Te}-127 \mathrm{~m}$ \\
\hline ZA052128 & $52-\mathrm{Te}-128$ \\
\hline ZA052129.M & $52-\mathrm{Te}-129 \mathrm{~m}$ \\
\hline ZA052130 & $52-\mathrm{Te}-130$ \\
\hline ZA052132 & $52-\mathrm{Te}-132$ \\
\hline ZA053127 & $53-I-127$ \\
\hline ZA053129 & $53-I-129$ \\
\hline ZA053130 & $53-I-130$ \\
\hline ZA053131 & $53-I-131$ \\
\hline ZA053135 & $53-I-135$ \\
\hline ZA054124 & $54-\mathrm{Xe}-124$ \\
\hline ZA054126 & $54-\mathrm{Xe}-126$ \\
\hline ZA054128 & $54-\mathrm{Xe}-128$ \\
\hline ZA054129 & $54-\mathrm{Xe}-129$ \\
\hline ZA054130 & $54-\mathrm{Xe}-130$ \\
\hline ZA054131 & $54-\mathrm{Xe}-131$ \\
\hline ZA054132 & $54-\mathrm{Xe}-132$ \\
\hline ZA054133 & $54-\mathrm{Xe}-133$ \\
\hline ZA054134 & $54-\mathrm{Xe}-134$ \\
\hline ZA054135 & $54-\mathrm{Xe}-135$ \\
\hline ZA054136 & $54-\mathrm{Xe}-136$ \\
\hline ZA055133 & $55-\mathrm{Cs}-133$ \\
\hline ZA055134 & $55-\mathrm{Cs}-134$ \\
\hline ZA055135 & $55-\mathrm{Cs}-135$ \\
\hline ZA055136 & $55-\mathrm{Cs}-136$ \\
\hline ZA055137 & $55-\mathrm{Cs}-137$ \\
\hline ZA056134 & $56-\mathrm{Ba}-134$ \\
\hline ZA056135 & $56-\mathrm{Ba}-135$ \\
\hline ZA056136 & $56-\mathrm{Ba}-136$ \\
\hline ZA056137 & $56-\mathrm{Ba}-137$ \\
\hline ZA056138 & $56-\mathrm{Ba}-138$ \\
\hline ZA056140 & $56-\mathrm{Ba}-140$ \\
\hline ZA057139 & 57-La-139 \\
\hline ZA057140 & $57-\mathrm{L} a-140$ \\
\hline ZA058140 & $58-\mathrm{Ce}-140$ \\
\hline ZA058141 & $58-\mathrm{Ce}-141$ \\
\hline ZA058142 & $58-\mathrm{Ce}-142$ \\
\hline ZA058143 & $58-\mathrm{Ce}-143$ \\
\hline ZA058144 & $58-\mathrm{Ce}-144$ \\
\hline ZA059141 & $59-\operatorname{Pr}-141$ \\
\hline ZA059142 & $59-\operatorname{Pr}-142$ \\
\hline ZA059143 & $59-\operatorname{Pr}-143$ \\
\hline $\mathrm{ZA0} 60142$ & $60-\mathrm{Nd}-142$ \\
\hline ZA060143 & $60-N d-143$ \\
\hline ZA0 60144 & $60-\mathrm{Nd}-144$ \\
\hline $\mathrm{ZA0} 60145$ & $60-\mathrm{Nd}-145$ \\
\hline $\mathrm{ZA0} 60146$ & $60-\mathrm{Nd}-146$ \\
\hline ZA060147 & $60-\mathrm{Nd}-147$ \\
\hline
\end{tabular}

\begin{tabular}{|c|c|}
\hline Filename & Material \\
\hline $\mathrm{ZA} 060148$ & $60-N d-148$ \\
\hline $\mathrm{ZA} 060150$ & $60-N d-150$ \\
\hline ZA061147 & $61-\mathrm{Pm}-147$ \\
\hline $\mathrm{ZA} 061148$ & $61-P m-148$ \\
\hline $\mathrm{ZA061148.M}$ & $61-\mathrm{Pm}-148 \mathrm{~m}$ \\
\hline ZA061149 & $61-\mathrm{Pm}-149$ \\
\hline $\mathrm{ZA061151}$ & $61-P m-151$ \\
\hline $\mathrm{ZA062144}$ & $62-\mathrm{Sm}-144$ \\
\hline $\mathrm{ZA} 062147$ & $62-\mathrm{Sm}-147$ \\
\hline $\mathrm{ZA062148}$ & $62-\mathrm{Sm}-148$ \\
\hline $\mathrm{ZA062149}$ & $62-S m-149$ \\
\hline $\mathrm{ZA} 062150$ & $62-S m-150$ \\
\hline $\mathrm{ZA} 062151$ & $62-S m-151$ \\
\hline $\mathrm{ZA} 062152$ & $62-S m-152$ \\
\hline $\mathrm{ZA} 062153$ & $62-S m-153$ \\
\hline ZA062154 & $62-\mathrm{Sm}-154$ \\
\hline $\mathrm{ZA063151}$ & 63-Eu-151 \\
\hline $\mathrm{ZA063152}$ & 63-Eu-152 \\
\hline $\mathrm{ZA063153}$ & 63-Eu-153 \\
\hline ZA063154 & 63-Eu-154 \\
\hline ZA063155 & 63-Eu-155 \\
\hline $\mathrm{ZA} 063156$ & 63-Eu-156 \\
\hline ZA063157 & 63-Eu-157 \\
\hline $\mathrm{ZA} 064152$ & $64-G d-152$ \\
\hline $\mathrm{ZA} 064154$ & $64-G d-154$ \\
\hline $\mathrm{ZA} 064155$ & 64-Gd-155 \\
\hline ZA064156 & $64-G d-156$ \\
\hline ZA064157 & $64-G d-157$ \\
\hline $\mathrm{ZA064158}$ & $64-G d-158$ \\
\hline $\mathrm{ZA} 064160$ & $64-G d-160$ \\
\hline ZA065159 & $65-T b-159$ \\
\hline $\mathrm{ZA} 065160$ & $65-T b-160$ \\
\hline $\mathrm{ZA} 066160$ & $66-D_{y}-160$ \\
\hline $\mathrm{ZA066161}$ & $66-D y-161$ \\
\hline ZA066162 & $66-D_{y}-162$ \\
\hline $\mathrm{ZA066163}$ & $66-D y-163$ \\
\hline $\mathrm{ZA} 066164$ & $66-\mathrm{Dy}-164$ \\
\hline $\mathrm{ZA} 067165$ & 67-Ho-165 \\
\hline $\mathrm{ZA} 068166$ & $68-\operatorname{Er}-166$ \\
\hline ZA068167 & $68-\operatorname{Er}-167$ \\
\hline ZA071175 & 71-Lu-175 \\
\hline $\mathrm{ZA} 071176$ & $71-\mathrm{Lu}-176$ \\
\hline $\mathrm{ZA} 072000$ & 72-Hf-Nat \\
\hline $\mathrm{ZA} 072174$ & $72-\mathrm{Hf}-174$ \\
\hline ZA072176 & $72-\mathrm{Hf}-176$ \\
\hline $\mathrm{ZA} 072177$ & 72-Hf-177 \\
\hline $\mathrm{ZA} 072178$ & $72-\mathrm{Hf}-178$ \\
\hline $\mathrm{ZA} 072179$ & 72-Hf-179 \\
\hline $\mathrm{ZA} 072180$ & $72-H f-180$ \\
\hline ZA073181 & 73-Ta-181 \\
\hline ZA073182 & 73-Ta-182 \\
\hline $\mathrm{ZA} 074000$ & 74-W -Nat \\
\hline $\mathrm{ZA} 074182$ & $74-W-182$ \\
\hline $\mathrm{ZA} 074183$ & $74-W-183$ \\
\hline $\mathrm{ZA} 074184$ & $74-W-184$ \\
\hline
\end{tabular}

\begin{tabular}{|c|c|}
\hline Filename & Material \\
\hline ZA074186 & $74-W-186$ \\
\hline ZA075185 & $75-\operatorname{Re}-185$ \\
\hline ZA075187 & $75-\operatorname{Re}-187$ \\
\hline ZA077191 & $77-I r-191$ \\
\hline ZA077193 & $77-I r-193$ \\
\hline ZA079197 & 79-Au-197 \\
\hline ZA082206 & $82-\mathrm{Pb}-206$ \\
\hline ZA082207 & $82-\mathrm{Pb}-207$ \\
\hline ZA082208 & $82-\mathrm{Pb}-208$ \\
\hline ZA083209 & $83-B i-209$ \\
\hline ZA090230 & $90-T h-230$ \\
\hline ZA090232 & $90-T h-232$ \\
\hline ZA091231 & $91-\mathrm{Pa}-231$ \\
\hline ZA091232 & $91-\mathrm{Pa}-232$ \\
\hline ZA091233 & $91-\mathrm{Pa}-233$ \\
\hline ZA092232 & $92-U-232$ \\
\hline ZA092233 & $92-U-233$ \\
\hline ZA092234 & $92-U-234$ \\
\hline ZA092235 & $92-U-235$ \\
\hline ZA092236 & $92-U-236$ \\
\hline ZA092237 & $92-U-237$ \\
\hline ZA092238 & $92-U-238$ \\
\hline ZA093236 & $93-N p-236$ \\
\hline ZA093237 & $93-N p-237$ \\
\hline ZA093238 & $93-N p-238$ \\
\hline ZA093239 & $93-N p-239$ \\
\hline ZA094236 & $94-\mathrm{Pu}-236$ \\
\hline ZA094237 & $94-\mathrm{Pu}-237$ \\
\hline ZA094238 & $94-\mathrm{Pu}-238$ \\
\hline ZA094239 & $94-\mathrm{Pu}-239$ \\
\hline ZA094240 & $94-\mathrm{Pu}-240$ \\
\hline ZA094241 & $94-\mathrm{Pu}-241$ \\
\hline ZA094242 & $94-\mathrm{Pu}-242$ \\
\hline ZA094243 & $94-\mathrm{Pu}-243$ \\
\hline ZA094244 & $94-\mathrm{Pu}-244$ \\
\hline ZA095241 & 95-Am-241 \\
\hline ZA095242 & $95-A m-242$ \\
\hline ZA095242.M & $95-A m-242 m$ \\
\hline ZA095243 & $95-A m-243$ \\
\hline ZA096241 & $96-\mathrm{Cm}-241$ \\
\hline ZA096242 & $96-\mathrm{Cm}-242$ \\
\hline ZA096243 & $96-\mathrm{Cm}-243$ \\
\hline ZA096244 & $96-\mathrm{Cm}-244$ \\
\hline ZA096245 & $96-\mathrm{Cm}-245$ \\
\hline ZA096246 & $96-\mathrm{Cm}-246$ \\
\hline ZA096247 & $96-\mathrm{Cm}-247$ \\
\hline ZA096248 & $96-\mathrm{Cm}-248$ \\
\hline ZA097249 & $97-B k-249$ \\
\hline ZA098249 & $98-C f-249$ \\
\hline ZA098250 & $98-C f-250$ \\
\hline ZA098251 & $98-C f-251$ \\
\hline ZA098252 & $98-C f-252$ \\
\hline ZA098253 & $98-C f-253$ \\
\hline ZA099253 & $99-E s-253$ \\
\hline
\end{tabular}


Fig.1: Effect of Doppler Broadening on Resonance Cross Sections
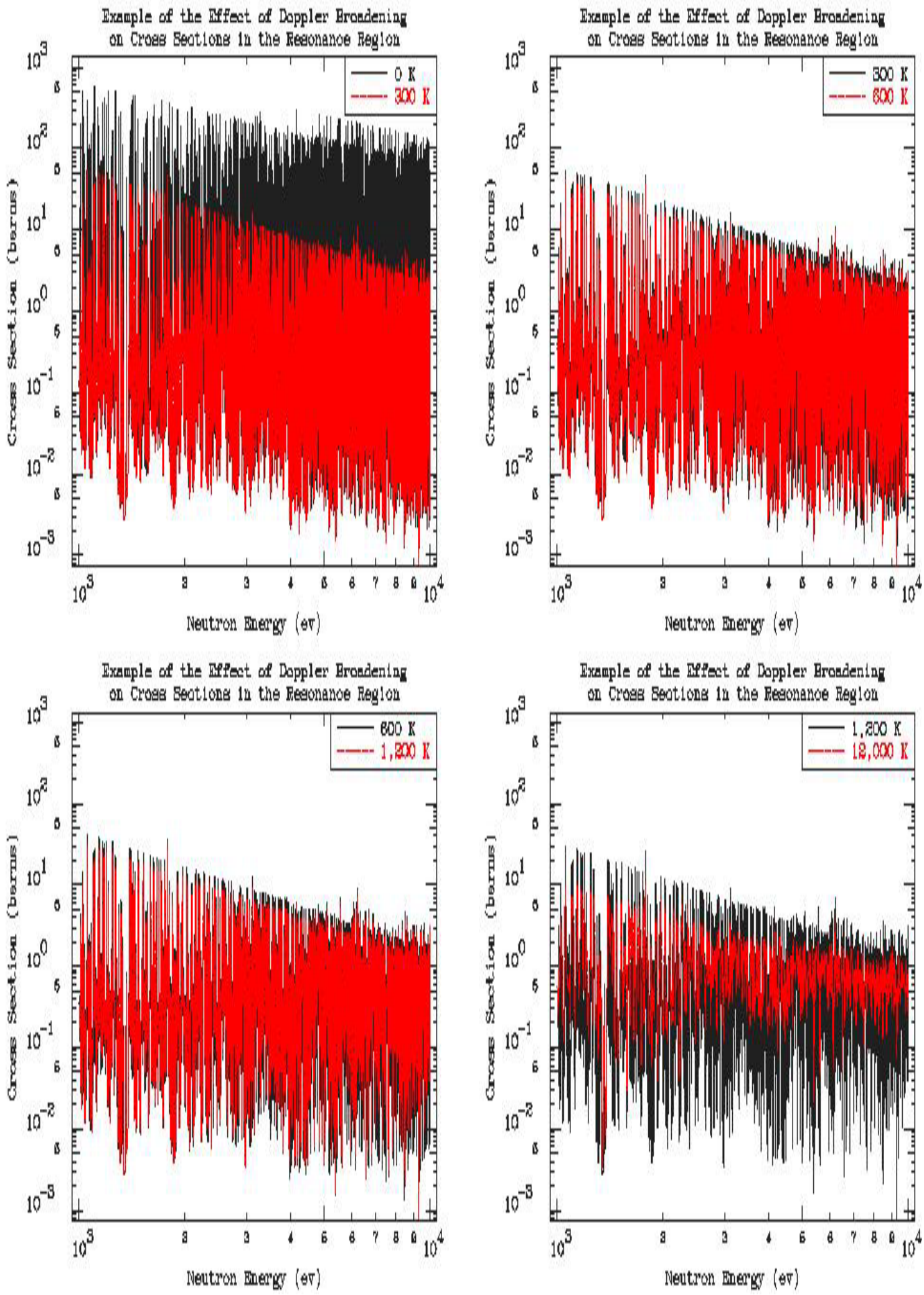
Fig.2: Effect of Doppler Broadening on Resonance Cross Sections
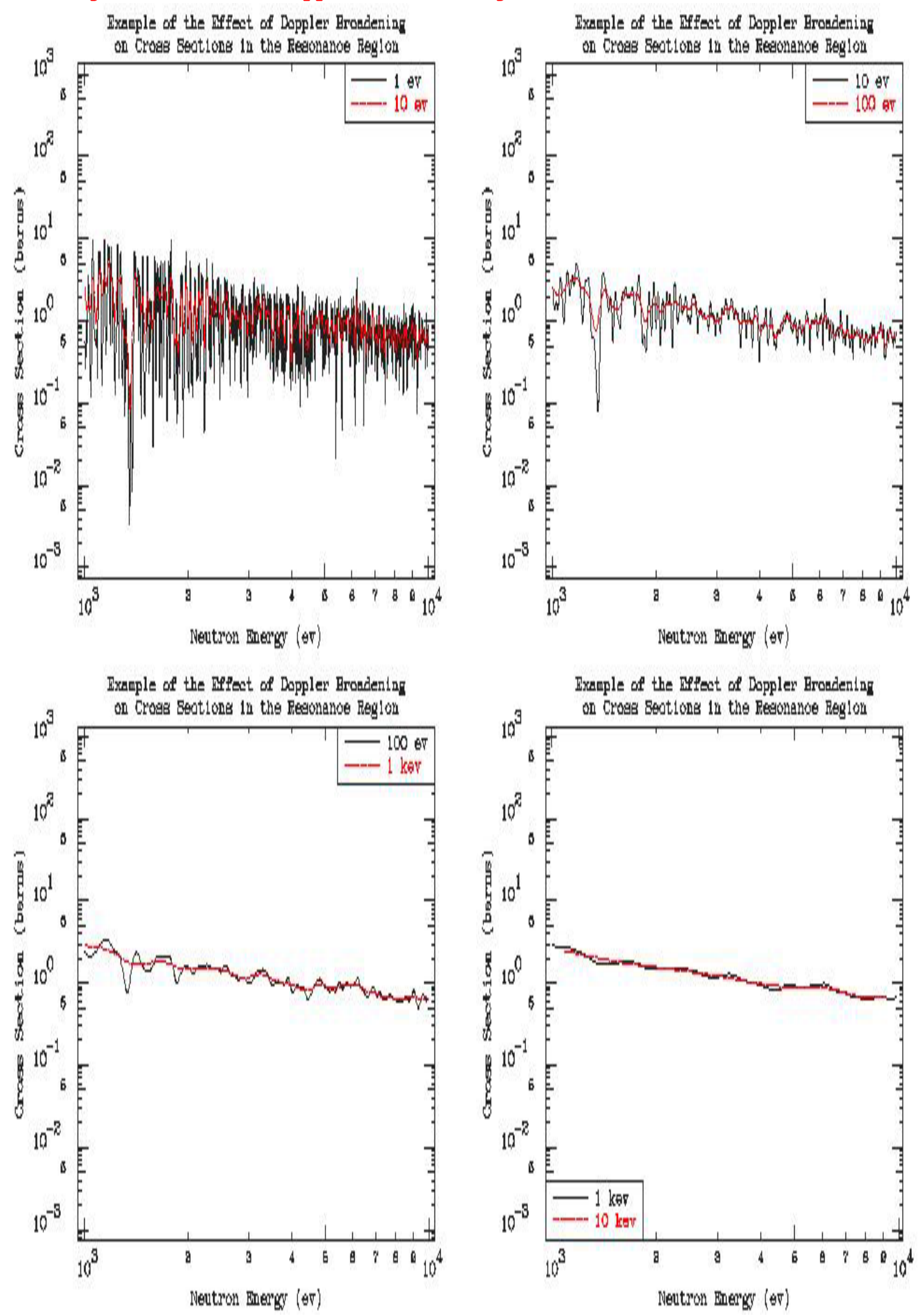

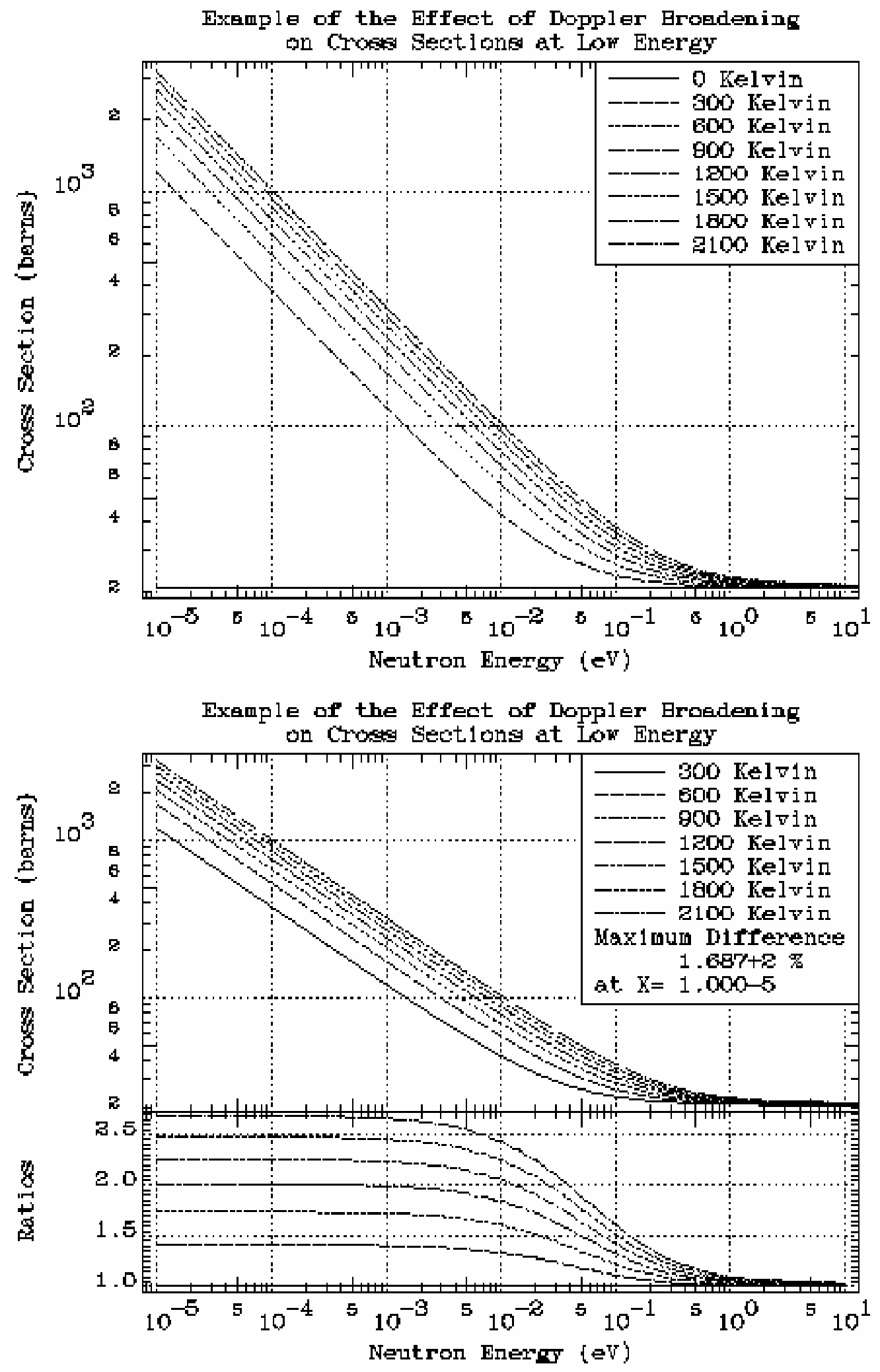
ENDF/B-VI, Release 8 
University of California

Lawrence Livermore National Laboratory

Technical Information Department

Livermore, CA 94551

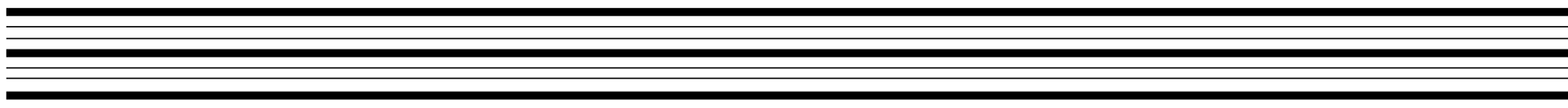

